by the suspension method compared with previously published results may be due to the very small particle sizes in the suspension prepared by shaking with glass beads, and that the finer the suspension the more closely will the result approach the M.I.C. by the whole-colony method.

The apparent resistance of colonies to antibiotics has been shown to be solely a resistance to a bactericidal effect, and probably due to physical properties of the colony, into which it is difficult for the antibiotic to diffuse.

The importance of colony resistance to antibiotics in the treatment of patients remains, for in infection with $A$. israelii the organism is always found in colonial form. Although inhibition of colony growth can be obtained at very low levels of suitable antibiotics it is usually assumed that bactericidal levels of antibiotics are required for the successful treatment of actinomycosis. However, these in vitro experiments suggest that, at least for the strains examined, relatively low serum levels of the most effective antibiotics, if sustained for a sufficiently long period, will eradicate the infection.

The in vitro results confirm benzylpenicillin as the antibiotic of choice, but the organism is also shown to be very sensitive to phenoxymethylpenicillin, phenethicillin, and erythromycin.

No evidence has been found of the variation of inhibitory concentrations of antibiotic with different strains of actinomyces, which has been found by other authors (Strauss et al., 1951). There is a noticeable constancy in the results found for all the strains throughout the series of experiments, confirming in this respect the results of Suter and Vaughan (1955). The number of strains tested in this series is small, and other strains of different antibiotic sensitivities may well exist. However, the variations in previously reported results may also be due to the use of inocula containing particles of different sizes. Such variations in particle size would arise from the use of different methods for the preparation of suspensions of the organism and would affect the results obtained.

\section{Summary}

Minimum inhibitory concentrations of benzylpenicillin, phenoxymethylpenicillin, phenethicillin, méthicillin, cloxacillin, ampicillin, erythromycin, tetracycline, and demethylchlortetracycline against five strains of $A$. israelii from cervico-facial actinomycosis have been determined for whole colonies and for suspensions. The resistance of the colonies to antibiotics has been shown to be solely a resistance to bactericidal effect. No evidence of strain variation to the bacteriostatic effect of antibiotics has been found.

The assistance of Miss Joan Shepherd, senior technician in the bacteriology department, Eastman Dental Hospital, who carried out all the laboratory work for this investigation, is gratefully acknowledged. Messrs. Beecham Research Laboratories Ltd., Lederle Laboratories, Eli Lilly \& Co. Ltd., and Pfizer Ltd. supplied the antibiotics used in these experiments.

\section{REFERENCES}

Garrod, L. P. (1952). Brit. med. F., 1, 1263.

and Scowen, E. F. (1960). Brit. med. Bull., 16, 23

Holm, P. (1948). Acta path. microbiol. scand., 25, 376.

Strauss, R. E., Kligman, A. M., and Pillsbury, D. M. (1951). Amer. rev. Tuberc., 63, 441.

Suter, L. S., and Vaughan, B. F. (1955). Antibiot. and Chemother., 5, 557.

\title{
Comparison of Ampicillin and Chloramphenicol in Treatment of Paratyphoid Fever*
}

\author{
R. A. SLEET, $†$ M.B., CH.B., G. SANGSTER, $\ddagger$ M.D. ; J. MCC. MURDOCH,§ F.R.C.P.ED., M.R.C.P.GLASG.
}

Brit. med.f., 1964, 1, 148-150

Huckstep (1962) has reviewed and clarified the role of chloramphenicol in the treatment of the enteric fevers during the past ten years, but it has not been possible to evaluate the potential advantage of ampicillin over chloramphenicol, as no sufficiently large series has been reported. However, an opportunity to compare these antibiotics has been provided by the occurrence of a recent outbreak of paratyphoid fever in the Edinburgh area in which about 200 patients were involved. Salmonella paratyphi $B$-phage type Taunton-contaminating bakery products was primarily responsible for the outbreak, and details of the epidemiological aspects will be published elsewhere by others.

The in vitro activity and the high biliary concentration of ampicillin suggests that this penicillin is a suitable alternative to chloramphenicol. Successful results have been reported by Maddock (1962) in three patients with Salm. typhi infection and by Trafford et al. (1962) and Patel (1963) respectively in single patients, while Kennedy et al. (1963) obtained a satisfactory response in three patients although two required a second course with increased doses. In other salmonella infections results have been variable (Stewart et al., 1961 ; Ross

- From the City Hospital, Edinburgh.

+ Medical Registrar. $¥$ Physician. $\$$ Consultant Physician. et al., 1962 ; Tynes and Utz, 1962), but previous experience in this unit with Salm. paratyphi infections was favourable enough to warrant an extended trial. Two acutely ill patients and two of four carriers responded well, all but one having had chloramphenicol previously. The two failures were treated for three and four weeks with $3 \mathrm{~g}$. and $2 \mathrm{~g}$. daily respectively (Kennedy et al., 1963). Direct comparison with previously employed dose regimens was not possible as the duration of treatment varied and ampicillin dosage was between 50 and $200 \mathrm{mg} . / \mathrm{kg}$./day. Because of this it was decided to employ much higher doses of ampicillin, as previous work had suggested that they were more effective.

\section{Material and Methods}

Most of the patients were acutely ill in the earlier stages of the outbreak, and later, as might have been expected, more carriers were treated. The clinical picture showed the usual variation-from no symptomatology to typical paratyphoid fever.

Patients were admitted to the trial only when the diagnosis was confirmed either by bacteriological proof from blood or faeces or by a positive Widal reaction supported by 
good clinical evidence. Patients with acute gastro-enteritis without systemic involvement were classified as mild cases. Moderate illness in most of the patients was characterized by clinical paratyphoid fever, but in only a small number could this be regarded as severe. Gastro-enteritic symptoms only had occurred in most of the carriers. Respiratory symptoms predominated in 10 patients, while in six appendicectomy preceded the diagnosis in the early stages of the outbreak; one appendix was removed towards the end.

Chloramphenicol and ampicillin were given on a random but not "double-blind" basis for 14 days. The daily dose of chloramphenicol was $2 \mathrm{~g}$. for adults and $75 \mathrm{mg} . / \mathrm{kg}$. for children; the corresponding doses of ampicillin were $6 \mathrm{~g}$. and $200 \mathrm{mg}$. $/ \mathrm{kg}$. To the young chloramphenicol was given in the form of palmitate, while the ampicillin was removed from its capsule and mixed with jam or milk. If a patient failed to respond in 10 days it was decided to change the treatment to the other antibiotic after a blood culture had been taken. When blood was withdrawn for other reasons antibiotic blood levels were randomly estimated.

\section{Test of Cure}

After treatment, at least three days were allowed to pass before the first clearance specimens of stool and urine were taken. Most patients had a minimum of three negative stool and urine specimens at four-day intervals before discharge from hospital. A minimum of six clearance specimens, at similar intervals, was taken from food-handlers and from patients returning to other hospitals or institutions. Further follow-up consisted of six clearance specimens in the first month after discharge and two per month for the next five months.

Of 159 patients admitted to the unit with paratyphoid infection only 145 satisfied the criteria for admission to the trial. Of these, 31 had mild, 88 moderate, and 13 severe illnesses, while the remaining 13 patients were carriers. The patients'

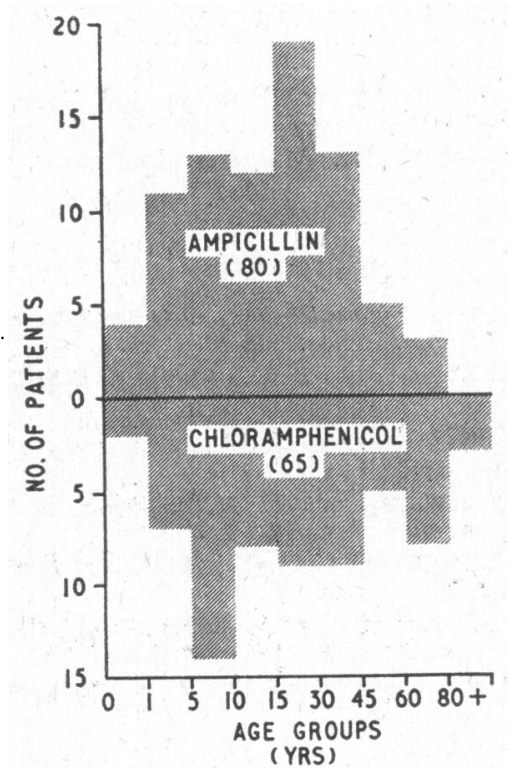

Frg. 1.-Age distribution of 145 patients.

TABLE I.-Distribution of Treatment in 145 Patients Related to Severity of Illness

\begin{tabular}{|c|c|c|c|c|c|c|}
\hline & $\begin{array}{l}\text { No. of } \\
\text { Patients }\end{array}$ & Group & Mild & Moderate & Severe & Carrier \\
\hline $\begin{array}{c}\text { Chloram- } \\
\text { phenicol (C) }\end{array}$ & 65\{ & 1. $\mathrm{C}+\mathrm{C}$ & $\begin{array}{r}12 \\
0\end{array}$ & $\begin{array}{r}35 \\
8\end{array}$ & $\begin{array}{l}8 \\
0\end{array}$ & $\begin{array}{l}2 \\
0\end{array}$ \\
\hline$\underset{\text { (A) }}{\text { Ampicillin }}$ & 80\{ & 3. $A$ & $\begin{array}{r}14 \\
5\end{array}$ & $\begin{array}{l}33 \\
12\end{array}$ & $\begin{array}{l}1 \\
4\end{array}$ & $\begin{array}{r}11 \\
0\end{array}$ \\
\hline & & Total & 31 & 88 & 13 & 13 \\
\hline
\end{tabular}

ages ranged from 6 weeks to 87 years (Fig. 1), and a high proportion were females-91 to 54 males. By random selection 65 patients were treated initially with chloramphenicol and 80 with ampicillin (Table I).

\section{Results}

Of the 101 patients with moderate or severe illness 76 gave positive blood cultures for Salm. paratyphi B. In 121 patients stool cultures were positive at some stage of the disease, but urinary excreters were few (3). All the isolates belonged to phage type Taunton except one which was phage type Dundee. In this instance the infection was contracted elsewhere. No strains were found to be resistant to either of the trial antibiotics by the disk-diffusion method, and the minimum inhibitory concentration (M.I.C.) of both lay between 2 and $4 \mu \mathrm{g} . / \mathrm{ml}$. for most organisms ; 14, however, were inhibited by $8 \mu \mathrm{g}$. of chloramphenicol and ampicillin per ml., and two by $16 \mu \mathrm{g} . / \mathrm{ml}$. Blood levels within two to four hours after a dose were always in excess of the M.I.C. required for either antibiotic. With ampicillin the levels were much higher than with chloramphenicol, $32 \mu \mathrm{g} . / \mathrm{ml}$. being commonly found after two to five hours, and the maximum for chloramphenicol was $8 \mu \mathrm{g} . / \mathrm{ml}$.

Apart from some value in diagnosis, the Widal reaction did not provide any useful information. In only one of the three patients who suffered a full relapse was the titre lower than that during the initial treatment. No significant alteration in the sensitivity pattern or M.I.C. was observed in post-treatment isolates.

The number of patients who received a single course of antibiotic was approximately equal-groups 1 and 3 . A full course of chloramphenicol was achieved in groups 1,2 , and $4 ; 18$ in group 4 had incomplete courses of ampicillin before chloramphenicol was substituted because of hypersensitivity reactions to ampicillin, and were therefore failures of this treatment. The three remaining patients in group 4 are comparable to the eight patients in group 2 in that all had full courses of both antibiotics (Table II).

TABLE II.-Distribution of Treatment in 145 Patients

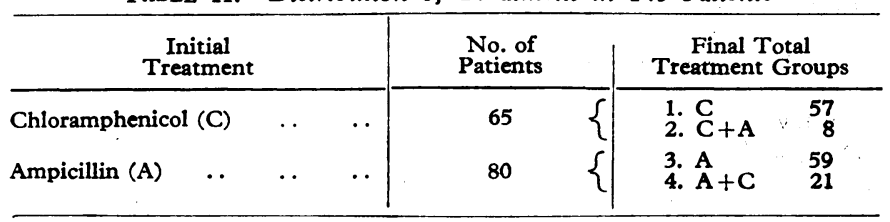

The response to ampicillin was usually slower than to chloramphenicol in that the temperature did not fall to normal levels so rapidly. The mean average duration of fever in those treated with chloramphenicol was three days, and six days in those who received ampicillin, but subjective improvement occurred earlier than the fall of temperature to normal in the latter group (Fig. 2). There were no other satisfactory clinical criteria for comparing the immediate effects of either treatment. For example, the variability of the number and nature of stools, both before and after treatment, made it impossible to assess this sign.

A second course of antibiotic was required for the following reasons, apart from drug hypersensitivity: (1) no response after 10 days of ampicillin in one patient ; (2) clinical and bacteriological relapse with positive blood culture in one patient who had received ampicillin and in two patients who had been treated with chloramphenicol ; (3) bacteriological relapse with positive stool culture in five patients treated with chlorampheni$\mathrm{col}$ and in one treated with ampicillin; (4) clinical relapse occurred in one patient after chloramphenicol therapy.

Table III shows the duration of follow-up in all patients. Table IV shows the relationship of bacteriological relapse in each treatment group to the duration of follow-up. It will be 
apparent that the highest incidence of bacteriological relapse occurred in the earlier months. Thirty-five patients were temporary excreters in the first two months after treatment and 15 have remained persistent excreters since then. The nine excreters occurring from the third month of follow-up were

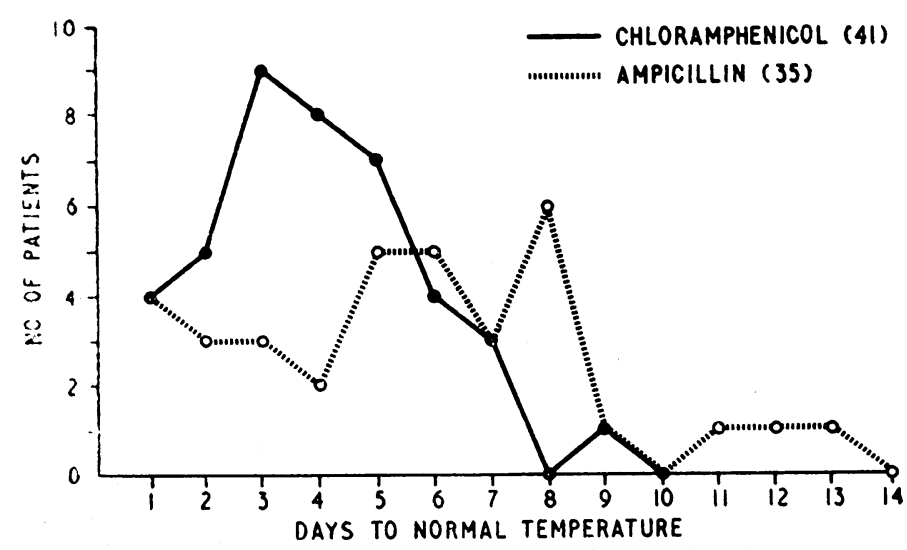

FIG. 2.-Temperature response in 76 patients (irrespective of duration of illness).

TABLE III.-Duration of Follow-up in 145 Patients

\begin{tabular}{|c|c|c|c|c|c|c|c|}
\hline \multirow{2}{*}{$\begin{array}{l}\text { Treatment } \\
\text { Group }\end{array}$} & \multicolumn{7}{|c|}{ Months after Treatment } \\
\hline & 1 & 2 & 3 & 4 & 5 & 6 & $6+$ \\
\hline $\begin{array}{l}\text { 1. } \mathrm{C} \\
\text { 2. } \mathrm{C}+\mathrm{A} \\
\text { 3. } \mathrm{A} \\
\text { 4. } \mathrm{A}+\mathrm{C}\end{array}$ & $\begin{array}{r}57 \\
8 \\
59 \\
21\end{array}$ & $\begin{array}{r}52 \\
6 \\
46 \\
17\end{array}$ & $\begin{array}{r}50 \\
6 \\
42 \\
16\end{array}$ & $\begin{array}{r}44 \\
4 \\
37 \\
13\end{array}$ & $\begin{array}{r}33 \\
3 \\
32 \\
10\end{array}$ & $\begin{array}{r}19 \\
1 \\
14 \\
3\end{array}$ & $\begin{array}{l}5 \\
0 \\
3 \\
0\end{array}$ \\
\hline Total & 145 & 121 & 114 & 98 & 78 & 37 & 8 \\
\hline
\end{tabular}

TABLE IV.-Number of Patients Showing Bacteriological Relapse in Each Treatment Group ${ }^{\star}$

\begin{tabular}{|c|c|c|c|c|c|c|c|}
\hline \multirow{2}{*}{$\begin{array}{c}\text { Treatment } \\
\text { Group }\end{array}$} & \multicolumn{6}{|c|}{ Post-treatment Period in Months } & \multirow{2}{*}{ Total } \\
\hline & 1st & 2nd & 3rd & 4th & 5 th & 6th & \\
\hline 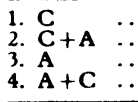 & $\begin{array}{c}18(7) \\
5 \\
15(3) \\
4\end{array}$ & $\begin{array}{l}4(1) \\
1 \\
1 \\
2\end{array}$ & $\begin{array}{l}2 \\
0 \\
0 \\
1\end{array}$ & $\begin{array}{l}1 \\
0 \\
2 \\
1\end{array}$ & $\begin{array}{l}1 \\
0 \\
1 \\
0\end{array}$ & $\begin{array}{l}0 \\
0 \\
0 \\
0\end{array}$ & $\begin{array}{r}26 \\
6 \\
19 \\
8\end{array}$ \\
\hline Total & 42 & 8 & 3 & 4 & 2 & 0 & 59 \\
\hline
\end{tabular}

temporary. Only groups 1 and 3 can be directly compared, and of 92 patients who have been followed up for three months or more 50 were in group 1 and 42 in group 3 . The total failures, both temporary and persistent, in these groups numbered 26 $(52 \%)$ and $19(41 \%)$ respectively. Eight of group 1 have become persistent faecal excreters, while only three have occurred in group 3 (see Table IV). The possibility exists that some of the temporary excreters may relapse and become persistent carriers.

\section{Discussion}

If high doses of ampicillin are necessary for the treatment of Salm. paratyphi infections, and there is a risk of sensitization to this penicillin in about one-fifth of the treated patients, as has been recently reported (Kennedy et al., 1963), this must be balanced against the much more serious risk of chloramphenicolinduced marrow aplasia. This is undoubtedly rare and almost always fatal, while the sensitization phenomena to ampicillin are mild and much less serious. If these considerations are taken into account it would seem from the results obtained in this trial that ampicillin is an effective treatment for paratyphoid fever. It is at a disadvantage where sensitization occurs, but it appears to have more therapeutic efficacy and less potential toxicity, especially for the asymptomatic biliary carrier. Further, repeated courses, or even more prolonged courses than have been used in this trial, would show a definite safety advantage over chloramphenicol. No serious toxicity was produced by either antibiotic in this trial. There was no previous history of penicillin allergy in those patients who received ampicillin.

The conclusion cannot be firmly reached that ampicillin should take precedence over chloramphenicol in Salm. paratyphi infections. Ampicillin may possibly be better for the initial treatment of the carrier, based on the fact that it was successful ir. 10 of the 11 patients, as compared with one of two receiving chloramphenicol.

There is the question of high cost of treatment with ampicillin compared with chloramphenicol, which might at present limit its widespread use, but it can be looked upon as a useful alternative in the patient who has failed to respond to chloramphenicol.

\section{Summary}

An outbreak of Salm. paratyphi infection in the Edinburgh area provided the opportunity to compare the relative efficacy of ampicillin and chloramphenicol treatment in 80 and 65 patients respectively. Treatment was randomized, and from the results obtained it appears that ampicillin in high doses can be used as an alternative to chloramphenicol. This is especially the case for the asymptomatic biliary carrier and the patient who has failed to respond to an initial course of chloramphenicol.

We are grateful to Dr. E. Knudsen, of Beecham Research Laboratories, England, for generous supplies of ampicillin. Our thanks are also due to Dr. Margaret Calder for bacteriological assistance.

\section{REFERENCES}

Huckstep, R. L. (1962). Typhoid Fever and Other Salmonella Infections. Livingstone, Edinburgh and London.

Kennedy, W. P. U., Wallace, A. T., and Murdoch, J. McC. (1963). Brit. med. 7., 2, 962.

Maddock, C. R. (1962). Lancet, 1, 918.

Patel, K. M. (1963). Ibid., 1, 1378.

Ross, S., Lovrien, E. W., Zaremba, E. A., Bourgeois, L., and Puig, J. R. (1962). F. Amer. med. Ass., 182, 238.

Stewart, G. T., Coles, H. M. T., Nixon, H. H., and Holt, R. J. (1961). Brit. med. F., 2, 200.

Trafford, J. A. P., Maclaren, D. M., Lillicrap, D. A., Barnes, R. D. S. Houston, J. C., and Knox, R. (1962). Lancet, 1, 987.

Tynes, B. S., and Utz, J. P. (1962). Ann. intern. Med., 57, 871. 